\title{
A comparison of mechanical and ultrasonic anemometers for ampacity thermal rating in overhead lines
}

\author{
A. Laso ${ }^{1}$, M. Mañana ${ }^{1}$, A. Arroyo ${ }^{1}$, A. González ${ }^{2}$, R. Lecuna ${ }^{1}$ \\ ${ }^{1}$ Department of Electrical and Energy Engineering \\ E.T.S.I.I.T., Cantabria University \\ Campus of Las Llamas - 39005 Santander (Spain) \\ Phone/Fax number:+0034 942 201378, e-mail: mario.manana@unican.es \\ ${ }^{2}$ Viesgo Distribución S.L.
}

\begin{abstract}
.
CIGRE TB601 guide for thermal rating calculations recommends the use of ultrasonic anemometers over mechanical devices [1].

This paper aims to compare the mechanical and ultrasonic wind speed measurement technologies for the purpose of dynamic ampacity rating.

The comparison consists of applying the measurements of both anemometers (placed in the same spot) to the computation of ampacity in the same overhead line, and evaluating the diferences at different speed ranges.
\end{abstract}

\section{Anemometer comparison}

CIGRE TB601 guide for thermal rating calculations recommendation of ultrasonic anemometers is not only due to the higher specifications (Table. 1) but also to the mechanical issues of the cup devices.

The static friction turns the mechanical units useless under the $0.5 \mathrm{~m} / \mathrm{s}$ threshold, which added to the $\pm 0.5 \mathrm{~m} / \mathrm{s}$ accuracy makes the measurement very unreliable under 1 $\mathrm{m} / \mathrm{s}$. This fact is important because at low wind speed the cooling of the cable changes form convection to natural.

Table. 1. Ultrasonic Vs Mechanical. Specifications

\section{Key words}

Ampacity rating, anemometer, comparison.

\begin{tabular}{|c|c|c|c|c|}
\hline Technology & Range & Threshold & Resolution & Accuracy \\
\hline Three cups mechanical & $0-50 \mathrm{~m} / \mathrm{s}$ & $0.5 \mathrm{~m} / \mathrm{s}$ & Not provided & $0.5 \mathrm{~m} / \mathrm{s}$ \\
\hline Two dimensional ultrasonic & $0-60 \mathrm{~m} / \mathrm{s}$ & Not provided & $0.01 \mathrm{~m} / \mathrm{s}$ & $2 \% @ 12 \mathrm{~m} / \mathrm{s}$ \\
\hline
\end{tabular}

\section{Introduction}

Dynamic ampacity rating is one of the solutions available to improve the static rating of an overhead line at relatively low cost.

The dynamic rating is very sensitive to the wind speed as seen in the equations provided by Cigre [1] and IEEE algorithms [2,3].

This sensitivity makes the choice of the anemometer an important matter not to be taken lightly [4,5].

This paper shows the advantages of the ultrasonic anemometers over those based on mechanical elements by comparing the differences in the ampacity calculated using both technologies. The comparison will be held at different wind ranges in order to expose the weaknesses of mechanical devices at low speed.

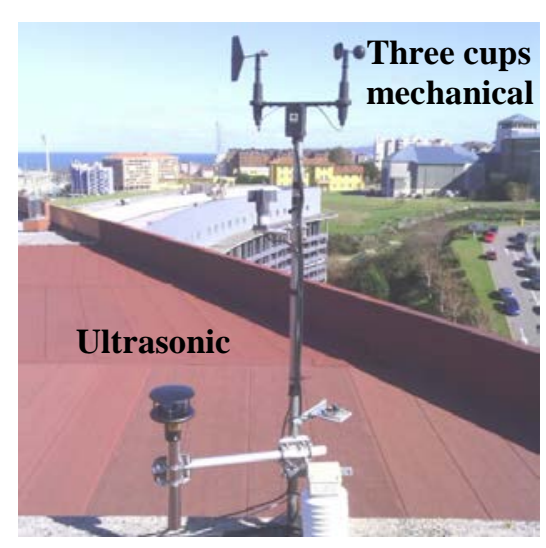

Fig. 1. Anemometers installation 


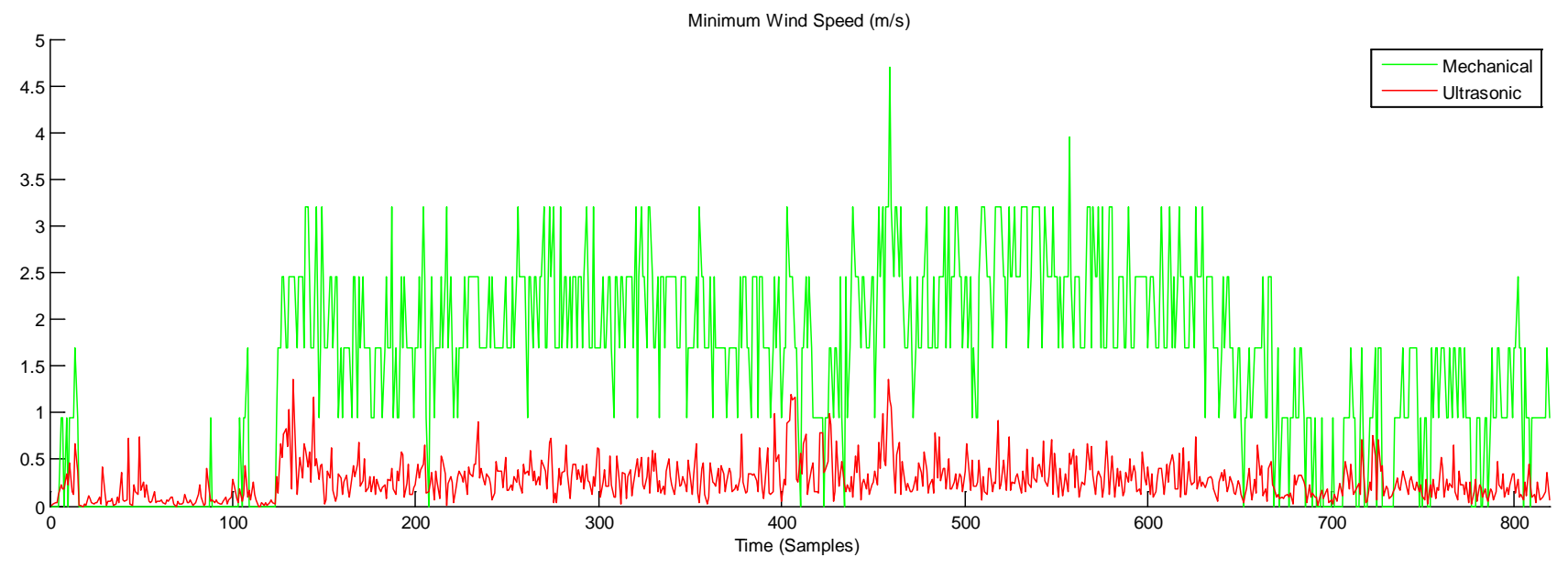

Fig. 2. Ultrasonic Vs Mechanical. Minimum wind speed

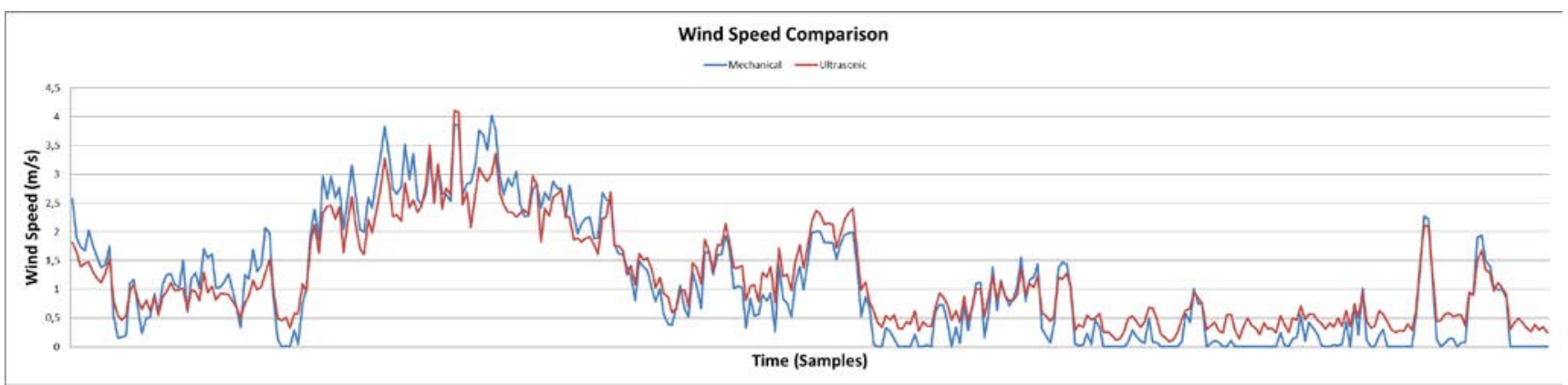

Fig. 3. Ultrasonic Vs Mechanical. Average wind speed comparison (one day)

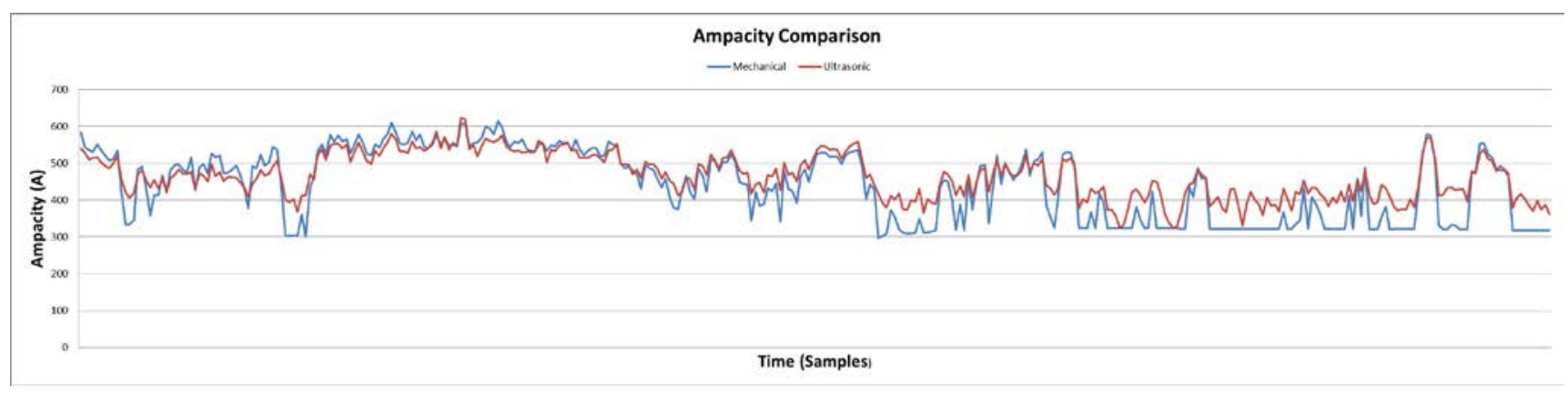

Fig. 4. Ultrasonic Vs Mechanical. Ampacity comparison (one day)

Fig. 1 shows the weather station with the anemometers used to obtain the data and placed in the roof of the E.T.S.I.I.T (School of Engineers) of the University of Cantabria.

In Fig. 2, each sample represents the minimum wind speed during a 1-minute interval with a 1-second measurement rate. It is easy to appreciate the low resolution of the mechanical anemometer as well as its $0.5 \mathrm{~m} / \mathrm{s}$ threshold value. Spinning inertia is also detected when minimum speed reaches $5 \mathrm{~m} / \mathrm{s}$ in the three cups device.
There is also the issue of maintenance and durability. Ultrasonic anemometers lack mobile parts, which makes them a priori better in this aspect.

\section{Ampacity comparison}

The comparison consists of applying the wind speed measurements of both anemometers (placed in the same spot) to the same overhead line. Any other variables stand the same for both cases so the differences in the 
results are only due to the differences in the anemometer data.

The overhead line consists of a LA-110 conductor with a static rate of $314 \mathrm{~A}$. in the northwest of Spain.

In figures Fig. 3 and Fig. 4, every sample corresponds to a 1-minute interval average with a 1-second measurement frequency. Despite the average calculation, it is easy to see the effect of the static friction in the mechanical device in Fig. 3. This translates in Fig. 3 into lower dynamic rating at very low wind speed while using a mechanical anemometer. The inertia is also present at higher wind speeds with a slightly increase on ampacity when over 2.5 $\mathrm{m} / \mathrm{s}$.

\section{Results}

After a closer analysis of the data, the mean square error of the ampacity measured with the mechanical anemometer with respect to the ultrasonic device proves the poor specifications of the first under $1 \mathrm{~m} / \mathrm{s}$ and especially under $0.5 \mathrm{~m} / \mathrm{s}$ (Table 2). Data from Table 2 is the result of 86,400 weather samples.

The wind speed thresholds in table 2 are in reference to the mechanical sensor. The corresponding ultrasonic measurement may be outside the specified range.

Table. 2. Mechanical anemometer. Mean square error

\begin{tabular}{|c|c|c|}
\cline { 2 - 3 } \multicolumn{1}{c|}{} & \multicolumn{2}{c|}{ Mean Square Error } \\
\cline { 2 - 3 } \multicolumn{1}{c|}{} & Wind speed & Ampacity \\
\hline All data & 0.11 & 2293 \\
\hline $\begin{array}{c}\text { Wind speed }<\mathbf{0 . 5} \\
\mathbf{~ m} / \mathbf{s}\end{array}$ & 0.12 & 5337 \\
\hline Wind speed $<\mathbf{1 ~ \mathbf { ~ m } / \mathbf { s }}$ & 0.10 & 4012 \\
\hline $\begin{array}{c}\mathbf{0 . 5} \mathbf{~ m} / \mathbf{s}<\text { Wind } \\
\text { speed }<\mathbf{1}\end{array}$ & 0.06 & 748 \\
\hline $\begin{array}{c}\mathbf{1} \mathbf{~ m} / \mathbf{s}<\text { Wind speed } \\
<\mathbf{2 . 5} \mathbf{~ m} / \mathbf{s}\end{array}$ & 0.08 & 422 \\
\hline $\begin{array}{c}\mathbf{2 . 5} \mathbf{~ m} / \mathbf{s}<\text { Wind } \\
\text { speed }\end{array}$ & 0.21 & 463 \\
\hline
\end{tabular}

It can also be appreciated that a lower wind speed error does not mean a lower ampacity error. This is due to two factors, the relative error and the sensitivity of the algorithm.

Despite the mean square error considering wind speeds between $0.5 \mathrm{~m} / \mathrm{s}$ and $1 \mathrm{~m} / \mathrm{s}$ is the lowest, its relative error is bigger than the relative error on the next step $(1 \mathrm{~m} / \mathrm{s}<$ wind speed $<2.5 \mathrm{~m} / \mathrm{s}$ ). This can be seen in the wind relative error histograms of figures Fig. 5 and Fig. 6.

Fig. 5, with wind speeds between $0.5 \mathrm{~m} / \mathrm{s}$ and $1 \mathrm{~m} / \mathrm{s}$, shows the relative error is under $20 \%$ only slightly over $50 \%$ of the time while it gets to almost $70 \%$ in Fig. 6, where the wind ranges from $1 \mathrm{~m} / \mathrm{s}$ to $2.5 \mathrm{~m} / \mathrm{s}$.
The ampacity algorithm is very sensitive to the wind at very low speeds and, in consequence, equal or even smaller error in the wind data may cause a higher error in ampacity results.

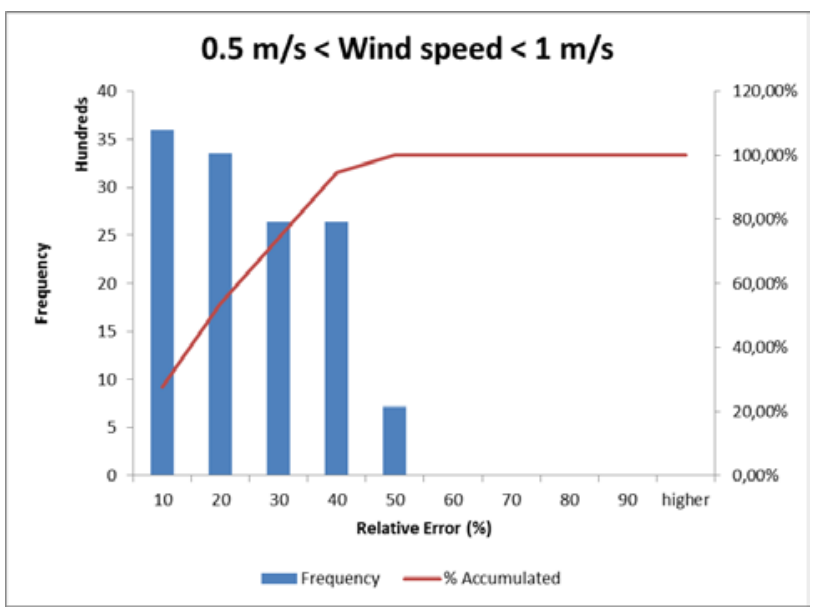

Fig. 5. Wind relative error histogram. $0.5<$ wind speed $<1 \mathrm{~m} / \mathrm{s}$

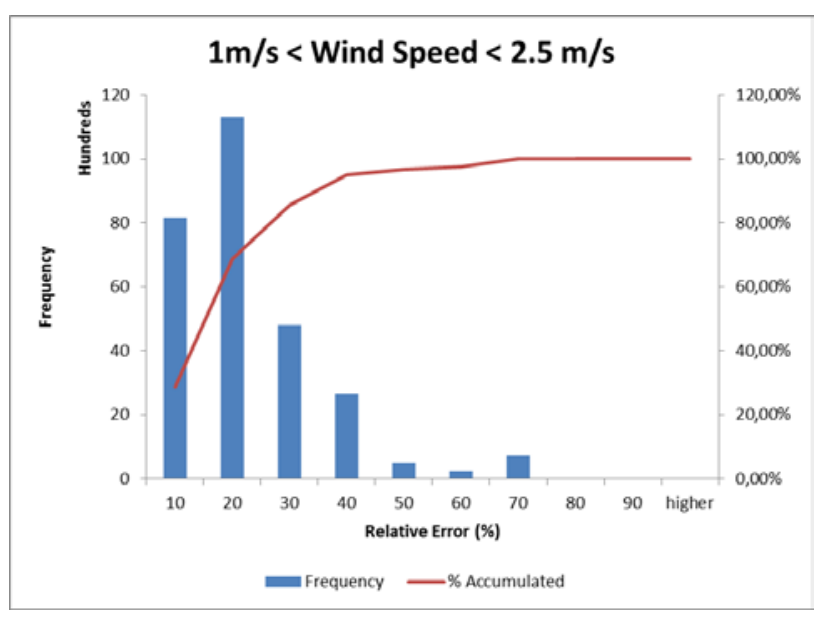

Fig. 6. Wind relative error histogram. $1<$ wind speed $<2.5 \mathrm{~m} / \mathrm{s}$

Fig. 7 shows the relative error of the wind at higher speeds. It can be seen that it is worse than in previous cases but because the lower sensitivity of the algorithm at these wind speeds, the resulting ampacity error stays low.

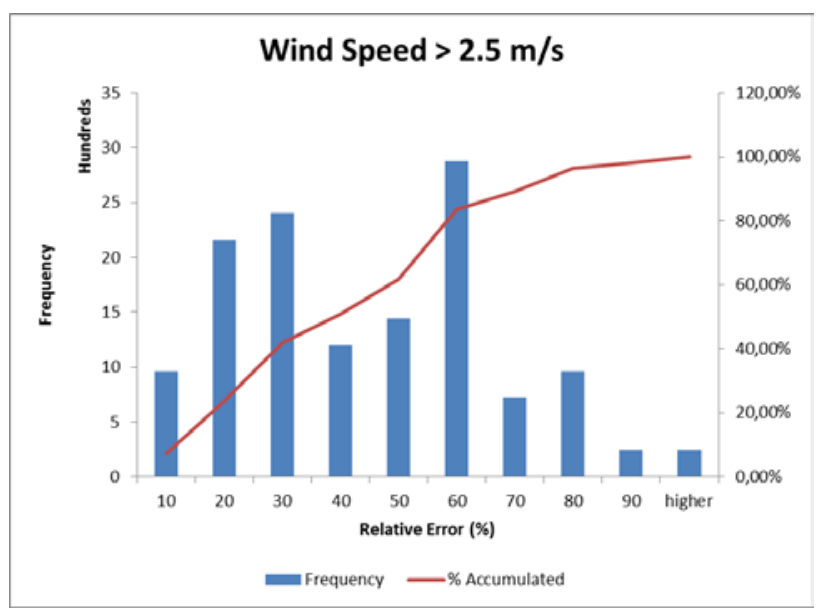

Fig. 7. Wind relative error histogram. $1<$ wind speed $<2.5 \mathrm{~m} / \mathrm{s}$ 
Figures Fig. 8 and Fig. 9 represent the histograms of the square error of the ampacity for different wind speeds. It can again be seen the huge difference between the two technologies when operating under $0.5 \mathrm{~m} / \mathrm{s}$ and the great improvement when over $1 \mathrm{~m} / \mathrm{s}$.

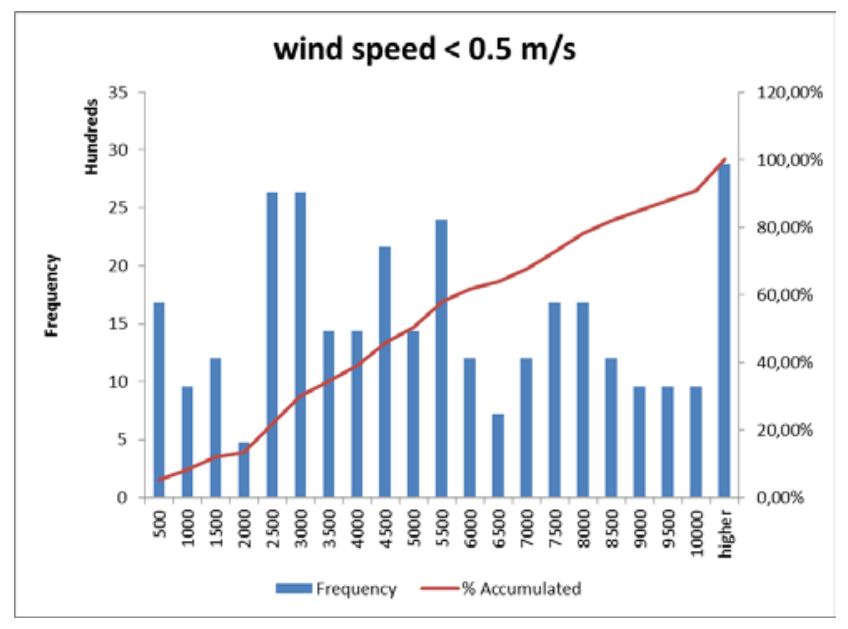

Fig. 8. Ampacity square error histogram. Wind speed $<0.5 \mathrm{~m} / \mathrm{s}$.

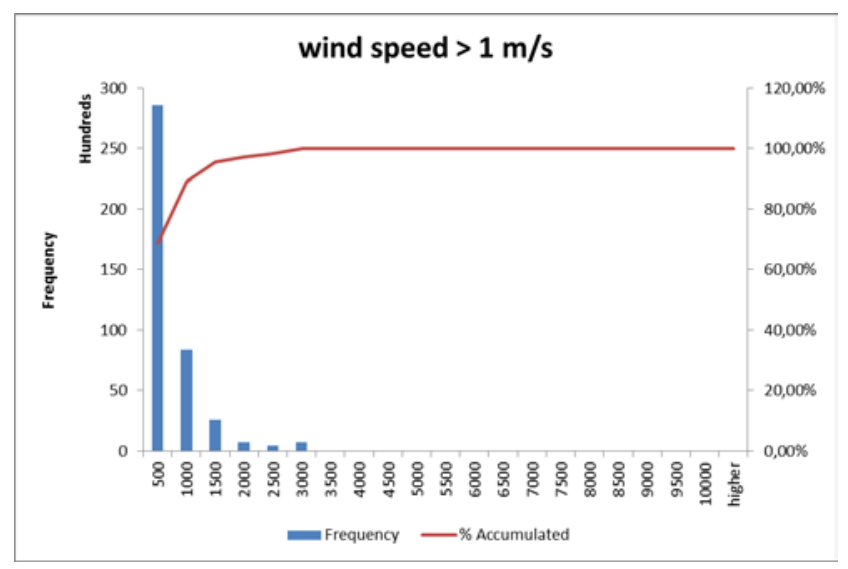

Fig. 9. Ampacity square error histogram. Wind speed $>1 \mathrm{~m} / \mathrm{s}$

\section{Conclusion}

The use of mechanical anemometers instead of ultrasonic devices for the purpose of dynamic ampacity rating has a direct impact in the calculations at very low wind speed due to the sensitivity of the algorithms to the wind and the limitations of the device. These differences are however in benefit of the safety of the conductor so the infrastructure is not at risk. Of course, this also means that the system operator will not take full advantage of the dynamic rating.

The difference in ampacity at higher speeds is relatively low and thought it goes against the conductor; the risk can be minimized by establishing a slightly reduced maximum temperature of the line in the algorithm.

The advantages of the ultrasonic sensor are not only in the better data provided but also in the additional durability due to the lack of mobile parts.
It is also important not to forget that the errors shown are in reference to an ultrasonic anemometer and not in reference to a known controlled wind speed.

\section{Acknowledgement}

This work was supported by the Spanish Government under the $\mathrm{R}+\mathrm{D}$ initiative INNPACTO with reference IPT2011-1447-920000 and Spanish R+D initiative with reference ENE2013-42720-R.

The authors of this article would also like to acknowledge Viesgo for its continuous support to the dynamic ampacity rating line of investigation.

\section{References}

[1] Cigre TB601: Guide for thermal rating calculations of overhead lines. December 2014.

[2] IEEE standard for calculating the current-temperature relationship of bare overhead conductors. IEEE Std 738-2012. (Revision of IEEE Std 738-2006). December 2013.

[3] Arroyo, A.; Castro, P.; Martinez, R.; Manana, M.; Madrazo, A.; Lecuna, R.; Gonzalez, A. Comparison between IEEE and CIGRE Thermal Behaviour Standards and Measured Temperature on a 132-kV Overhead Power Line. Energies 2015, 8(12), 13660-13671; doi:10.3390/en81212391. http://www.mdpi.com/1996-1073/8/12/12391

[4] Guide to Meteorological Instruments and Methods of Observation. WMO, No. 8. Sixth edition (1996).

[5] Meteorology. Sonic anemometers/thermometers. Acceptance test methods for mean wind measurements. International Organization for Standardization (2000). 